\title{
Consumption of diets high in prebiotic fiber or protein during growth influences the response to a high fat and sucrose diet in adulthood in rats
}

\author{
Alannah D Maurer ${ }^{1,2}$, Lindsay K Eller ${ }^{1}$, Megan C Hallam², Kim Taylor ${ }^{2}$, Raylene A Reimer ${ }^{1,2^{*}}$
}

\begin{abstract}
Background: Early dietary exposure can influence susceptibility to obesity and type 2 diabetes later in life. We examined the lasting effects of a high protein or high prebiotic fiber weaning diet when followed by a high energy diet in adulthood.

Methods: At birth, litters of Wistar rats were culled to 10 pups. At $21 \mathrm{~d}$ pups were weaned onto control (C), high prebiotic fiber (HF) or high protein (HP) diet. Rats consumed the experimental diets until 14 wk when they were switched to a high fat/sucrose (HFHS) diet for 6 wk. Body composition and energy intake were measured and an oral glucose tolerance test (OGTT) performed. Blood was analyzed for satiety hormones and tissues collected for real-time PCR.
\end{abstract}

Results: Weight gain was attenuated in male rats fed HF from 12 wk until study completion. In females there were early reductions in body weight that moderated until the final two wk of HFHS diet wherein HF females weighed less than HP. Final body weight was significantly higher following the high fat challenge in male and female rats that consumed HP diet from weaning compared to HF. Lean mass was higher and fat mass lower with HF compared to HP and compared to C in males. Energy intake was highest in HP rats, particularly at the start of HFHS feeding. Plasma glucose was higher in HP rats compared to HF during an OGTT. Plasma amylin was higher in HF females compared to $C$ and glucagon-like peptide-1 (GLP-1) was higher in HF rats during the OGTT. Leptin was higher in HP rats during the OGTT. HF upregulated GLUT 5 mRNA expression in the intestine and downregulated hepatic hydroxymethylglutaryl coenzyme A reductase. Male rats fed HP had higher hepatic triglyceride content than $\mathrm{C}$ or $\mathrm{HF}$.

Conclusion: These data suggest that while a long-term diet high in protein predisposes to an obese phenotype when rats are given a high energy diet in adulthood, consumption of a high fiber diet during growth may provide some protection.

\section{Background}

The prevalence of obesity has increased dramatically over the past two decades and is in turn contributing to the increased rates of comorbidities, particularly type 2 diabetes [1]. In children, the prevalence of obesity doubled and tripled in many countries between the 1970's and the 1990's [2]. Obesity in children has been linked to alterations in glucose metabolism which can lead to type 2 diabetes. Obesity is also an early risk

\footnotetext{
* Correspondence: reimer@ucalgary.ca

'Department of Biochemistry and Molecular Biology, University of Calgary,

3280 Hospital Drive NW, Calgary, T2N 4Z6, Canada

Full list of author information is available at the end of the article
}

factor for much of adult morbidity and mortality [3]. The best approach to preventing and/or treating obesity remains elusive.

A diet high in fiber is associated with various health benefits including reduction in colorectal cancer risk [4]. Fiber intake is also inversely associated with body mass index (BMI) and risk of type 2 diabetes [5,6]. Dietary recommendations for both the management and prevention of type 2 diabetes include high dietary fiber intake [7]. Various fiber sources have demonstrated benefits, including diets high in rye fiber blunting plasma glucose and insulin peaks [8] and psyllium fiber attenuating weight gain in mice fed a high-fat diet [9]. We have
() Biomed Central

C 2010 Maurer et al; licensee BioMed Central Ltd. This is an Open Access article distributed under the terms of the Creative Commons Attribution License (http://creativecommons.org/licenses/by/2.0), which permits unrestricted use, distribution, and reproduction in any medium, provided the original work is properly cited. 
previously shown that a highly fermentable fiber diet in rats increases the secretion of glucagon-like peptide (GLP-1), a potent insulin secretagogue that also slows gastric emptying, inhibits glucagon secretion, enhances $\beta$-cell proliferation and regulates food intake $[10,11]$.

High protein diets have become increasingly popular for weight loss [12]. The purported benefits of a high protein diet include increased satiety, increased thermogenesis and the maintenance of fat-free mass during weight loss [13]. Weight loss diets high in protein have also been associated with reductions in abdominal fat and low density lipoprotein cholesterol [14], reduction in serum triacylglycerol concentrations [15] and an improvement of cardiovascular risk profile [16]. Some evidence would suggest, however, that the satiating effect of protein is reduced with habitual protein intake [17].

It is now increasingly clear that response to diet in adulthood is programmed in part by the nutritional influences experienced during growth and development. A given genotype can give rise to distinct phenotypes depending on environmental conditions during development [18]. Exposure to specific nutritional environments during critical periods of development have long-term repercussions for health in adulthood, including increased risk of obesity and type 2 diabetes [19]. This 'developmental plasticity' is important as it allows a fetus to make adaptations that will favor its best chance of survival in the environment it expects to encounter after birth [20]. We now know that this plasticity continues well past birth [21] and nutrient intake in both pre- and postnatal periods can shape development. In addition, there is evidence suggesting that a "mismatch" between early environment (dietary or otherwise) and an organism's later environment can increase disease risk [22].

Independently, diets high in fiber or protein can contribute to various positive metabolic outcomes in adulthood depending on the condition they target. Whether or not long-term diets high in fiber or protein introduced at weaning provide protection against a high energy diet (a mismatched environment) in adulthood is not known. We have previously shown that high protein and high fiber diets introduced at weaning have differential effects on the expression of genes involved in glucose and lipid metabolism and inflammation in rats at 21 to 35 days of age [23]. Plasma GLP-1 was higher and leptin lower in young rats consuming a high fiber compared to a control or high protein diet [23]. Whether or not the pattern of gene expression and satiety hormone production established in young rats persists into adulthood when a high fat/sucrose diet challenge is given is not known. Therefore, our objective was to examine body weight, fat mass and the expression of satiety hormones and genes related to glucose and lipid metabolism in rats consuming a control, high fiber or high protein diet until adulthood and then undergoing a metabolic challenge with a high energy diet.

\section{Methods}

\section{Animals and diets}

Female Wistar rats were obtained from Charles River (Montreal, PQ, Canada) and housed in a temperature and humidity controlled room with a 12-h light/dark cycle. Following acclimatization, females were mated with male Wistar rats in wire-bottom cages to aid in identification of a copulation plug. Females were then isolated and given ad libitum access to control diet. All litters were culled to 10 pups ( 5 males and 5 females where possible) one day following birth to promote consistency of nourishment between litters during the suckling period. At weaning ( $21 \mathrm{~d})$, males and females were separated and 6 litters were placed on each of 3 experimental diets: control (C), high prebiotic fiber (HF, 22\% wt/wt) and high protein (HP, 40\% wt/wt). Composition of the diets is provided in Table 1. The HF diet used a combination of the prebiotic fibers, inulin and oligofructose, at a ratio of 1:1 (by weight). The prebiotic fiber blend was mixed in our laboratory but resembles commercially available Synergy 1 (Orafti BENEO, Tienen, Belgium). Rats consumed these diets until 14 wk of age (equivalent to young adulthood) when all rats were given a high fat/high sucrose (HFHS) diet for 6 weeks. The HFHS diet provided $40 \%$ of energy from fat and $45 \%$ from sucrose and was composed of (g/100 g): cornstarch (5); casein (14), sucrose (51), soybean oil (10), lard (10), Alphacel (5), AIN-93 M mineral mix (3.5), AIN-93 vitamin mix (1), L-cystine (0.3), and choline bitartrate (0.25). Adjusting the cornstarch component of

\section{Table 1 Experimental diet composition}

\begin{tabular}{|c|c|c|c|}
\hline Composition (g/kg) & Control* & High Protein & High Fiber \\
\hline Cornstarch & 465.7 & 205.7 & 325.5 \\
\hline Casein & 140 & 400 & 120.3 \\
\hline Dextrinized Cornstarch & 155 & 150 & 133.3 \\
\hline Sucrose & 100 & 100 & 86 \\
\hline Soybean Oil & 40 & 40 & 34.4 \\
\hline Alphacel & 50 & 50 & 43 \\
\hline AIN-93-MX & 35 & 35 & 30.1 \\
\hline AIN-93-VX & 10 & 10 & 8.6 \\
\hline L-Cystine & 1.8 & 1.8 & 1.6 \\
\hline Choline bitartrate & 2.5 & 2.5 & 2.2 \\
\hline Inulin/Oligofructose ${ }^{\Psi}$ & 0 & 0 & 215 \\
\hline
\end{tabular}

*Based on AIN-93 M purified diet to meet all nutritional requirements. The digestible energy of the control and high protein diets is $3.6 \mathrm{kcal} / \mathrm{g}$ and the high fiber diet slightly lower at $3.2 \mathrm{kcal} / \mathrm{g}$ due to the reduced energy content of the inulin and oligofructose.

Inulin supplied as Orafti Raftiline HP and oligofructose as Orafti Raftilose P95 in a 1:1 blend by weight (Quadra Chemicals Ltd., Burlington, ON, Canada). The energy value of the fiber blend $(1.5 \mathrm{kcal} / \mathrm{g})$ was used to substitute for an equicaloric amount of cornstarch in the high fiber diet. 
the experimental weaning diets has been used previously $[23,24]$ and results in minimal change to other essential nutrients. Food and water were provided ad libitum throughout the experiment. Principles of laboratory animal care were followed. The protocol was approved by the University of Calgary Animal Welfare Committee and conformed to the Guide for the Care and Use of Laboratory Animals.

\section{Food Intake and Body Composition}

Food intake was measured daily for a week every two weeks throughout the study by weighing each food cup to the nearest $0.1 \mathrm{~g}$ and then subtracting this weight from the previously measured weight. Body weight was measured once a week throughout the study. At the end of the six week HFHS feeding period, final body weight was measured and body composition determined under light anaesthesia using dual energy x-ray absorptiometry (DEXA) with software for small animal analysis (Hologic QDR 4500, Hologic, Inc., Bedford, MA).

\section{Oral glucose tolerance tests for glucose and satiety hormone levels}

One week prior to the end of the study, rats were feeddeprived overnight and a fasted blood sample taken vial tail nick. An oral glucose gavage $(2 \mathrm{~g} / \mathrm{kg})$ was administered and additional blood samples taken at 15, 30, 60, 90 , and $120 \mathrm{~min}$. Blood glucose was measured immediately using a One Touch Blood Glucose Meter (LifeScan, Inc, Milpitas, CA). At the end of the study, a second OGTT was performed for satiety hormone analysis. After an overnight fast, rats were anaesthetized with isoflurane and a fasting cardiac blood sample taken. Rats were allowed to wake and given an oral load of $2 \mathrm{~g} / \mathrm{kg}$ glucose. Subsequent blood samples were collected into chilled vacutainers (BD Biosciences, Mississauga, Ontario, Canada) with the addition of EDTA $(1 \mathrm{mg} / \mathrm{mL})$, aprotinin $(5 \times 105 \mathrm{KIU} / \mathrm{L})$ and the DPP-IV inhibitor, diprotin A $(34 \mu \mathrm{g} / \mathrm{ml}$; Calbiochem, La Jolla, CA) at 15,30 , and $60 \mathrm{~min}$ post-gavage. Plasma was stored at $-80^{\circ} \mathrm{C}$ until later analysis. After the final blood sample, the rats were over-anaesthetized and the cervical spine dislocated. The small intestine was excised, flushed, measured and weighed, then divided into three segments designated duodenum, jejunum and ileum. A distal piece of each section was immersed in liquid nitrogen and stored at $-80^{\circ} \mathrm{C}$ for later mRNA analysis. The colon, stomach, liver and cecum were also excised, measured, weighed, and stored at $-80^{\circ} \mathrm{C}$ for mRNA expression analysis.

\section{Plasma analysis}

A multiplex hormone assay kit and Luminex instrument were used to measure plasma insulin, leptin, total amylin and glucagon concentrations (Rat Endocrine LincoPlex Kit, Millipore, St. Charles, MO). The sensitivity of the multiplex kit was 55.6 pM for insulin and 6.2 pM for all other analytes. Concentrations of active GLP-1 were measured using a GLP-1 (Active) ELISA kit (LINCO Research, Millipore, St. Charles, MO). The lowest level of GLP-1 that can be detected by this assay is $2 \mathrm{pM}$.

\section{RNA extraction and Real-Time RT-PCR}

Total RNA was extracted from the stomach, small intestine, colon and liver using TRIzol reagent (Invitrogen, Carlsbad, USA). Reverse transcription was performed with an input of $1 \mu \mathrm{g}$ of total RNA using the 1st strand cDNA synthesis kit for RT-PCR (Invitrogen, Carlsbad, CA USA) with oligo $d(T) 15$ as a primer. The resultant cDNA was amplified using primers synthesized by the University of Calgary Core DNA Services (Calgary, AB, Canada) and analyzed by real time PCR. Primer sequences were according to our previous work [23]. The PCR reaction was heated for $1 \mathrm{~min} 30 \mathrm{~s}$ then 40 cycles at $95^{\circ} \mathrm{C}$ for $30 \mathrm{~s}, 60^{\circ} \mathrm{C}$ for $30 \mathrm{~s}$ and $72^{\circ} \mathrm{C}$ for $20 \mathrm{~s}$ in an iCycler instrument (BIO-RAD, Hercules, USA). A melt curve showed the melting point of the PCR product of interest. Actin was verified as a suitable housekeeping gene for the tissues of interest and actin primers included as an internal control in the reactions. The $2^{-\Delta \mathrm{CT}}$ method $[\Delta \mathrm{CT}=\mathrm{CT}$ (gene of interest) $-\mathrm{CT}$ (reference gene)] was utilized for the data analysis where threshold cycle (CT) indicates the fractional cycle number at which the amount of amplified target reaches a fixed threshold [25]. The $\triangle \mathrm{CT}$ is the difference in threshold cycles for the gene of interest and actin.

\section{Hepatic triglyceride and cholesterol content}

Triglyceride and cholesterol contents in samples of liver tissue were measured according to our previously published protocol [26]. Values are expressed as $\mathrm{mg}$ of triglyceride or cholesterol per $\mathrm{mg}$ of protein in the liver samples.

\section{Statistics}

All data are presented as mean \pm SE. A multivariate ANOVA was used to evaluate differences between groups with post hoc tests using Bonferroni correction. Diet and sex were included as fixed factors for physical characteristics, gene expression data, triglyceride and cholesterol content. Changes in glucose and hormone levels during the OGTT and longitudinal body weight and energy intake data were analyzed with repeated measures ANOVA. Throughout the analysis, when no sex differences were found data was combined for further analysis. Differences were considered significant at $\mathrm{p} \leq 0.05$. Statistical analyses were performed using SPSS v 16.0 software (SPSS Inc., Chicago, IL). 


\section{Results}

Body composition, energy intake and organ weights

Body weight was similar across all groups of male rats until 12 wk of age when the magnitude of weight gain slowed significantly in the HF fed rats compared to HP and $\mathrm{C}(\mathrm{p}<0.05$, Figure $1 \mathrm{~A})$. When the rats were switched to a HFHS diet (Figure 1B), HF rats had significantly lower body weight than $\mathrm{C}$ and $\mathrm{HP}$ at 15 and 16 wk of age $(\mathrm{p}<0.05)$. From $17 \mathrm{wk}$ to the end of the study, HP were significantly heavier than HF rats ( $\mathrm{p}<$ 0.05). In females, the HF diet was associated with a lower body weight at early time points than in the males (Figure 1C). At 4 wk of age, HF rats had lower body weight than $\mathrm{C}$ and HP rats while in weeks 5 through 8 , HF was lower than HP $(\mathrm{p}<0.05)$. The magnitude of difference in weight gain was smaller in females compared to males when switched to the HFHS diet (Figure 1D). At 19 and 20 wk of age, the HP female rats were significantly heavier than HF rats $(\mathrm{p}<0.05)$. Final body weight in male and female rats raised on the HP was higher than the HF group (Table 2). Body fat was higher in HP male $(p=0.001)$ and female $(\mathrm{p}=0.005)$ rats compared to $\mathrm{HF}$ and higher than $\mathrm{C}(\mathrm{p}=$ $0.001)$ in males. Percent lean mass was significantly lower in HP compared to $\mathrm{C}$ and HF in males ( $\mathrm{p}=$ $0.001)$. In females, HP was lower than HF $(p=0.003)$ but not $\mathrm{C}$. Weight gain in male rats while they consumed the $\mathrm{C}, \mathrm{HF}$, or HP diet was significantly lower in $\mathrm{HF}$ versus $\mathrm{C}$ and $\mathrm{HP}$ rats $(419 \pm 10 \mathrm{~g} ; 474 \pm 10 \mathrm{~g} ; 496 \pm$ 13 g respectively in $\mathrm{HF}, \mathrm{C}$, and $\mathrm{HP} ; \mathrm{p}=0.001)$. When switched to the HFHS diet for $6 \mathrm{wk}$, weight gain remained lower in $\mathrm{HF}$ versus $\mathrm{HP}$ rats $(45 \pm 6 \mathrm{~g} ; 57 \pm$ $6 \mathrm{~g} ; 64 \pm 4$ g respectively in $\mathrm{HF}, \mathrm{C}$, and HP; $\mathrm{p}=0.07)$. In females, the lower weight gain that occurred during wk 3 to wk 14 and during HFHS feeding was not significantly different from $\mathrm{C}$ and HP. Energy intake was higher in HP males compared to $\mathrm{HF}$ and $\mathrm{C}$ at 12 wk of age $(\mathrm{p}=0.02$, Figure $2 \mathrm{~A})$. HF rats had lower energy intake at 14 and 16 wk compared to $\mathrm{C}$ and $\mathrm{HP}$ and lower than HP at wk 20 ( $\mathrm{p}<0.05)$. In females, energy intake was lower in HF rats at wk 12 compared to $\mathrm{C}$ $(\mathrm{p}=0.05$, Figure $2 \mathrm{~B})$ and lower than HP rats at 14 and $20 \mathrm{wk}(\mathrm{p}<0.05)$. HP rats had high energy intake at 16 and 18 wk compared to $C$ and HF rats $(\mathrm{p}=0.04)$.

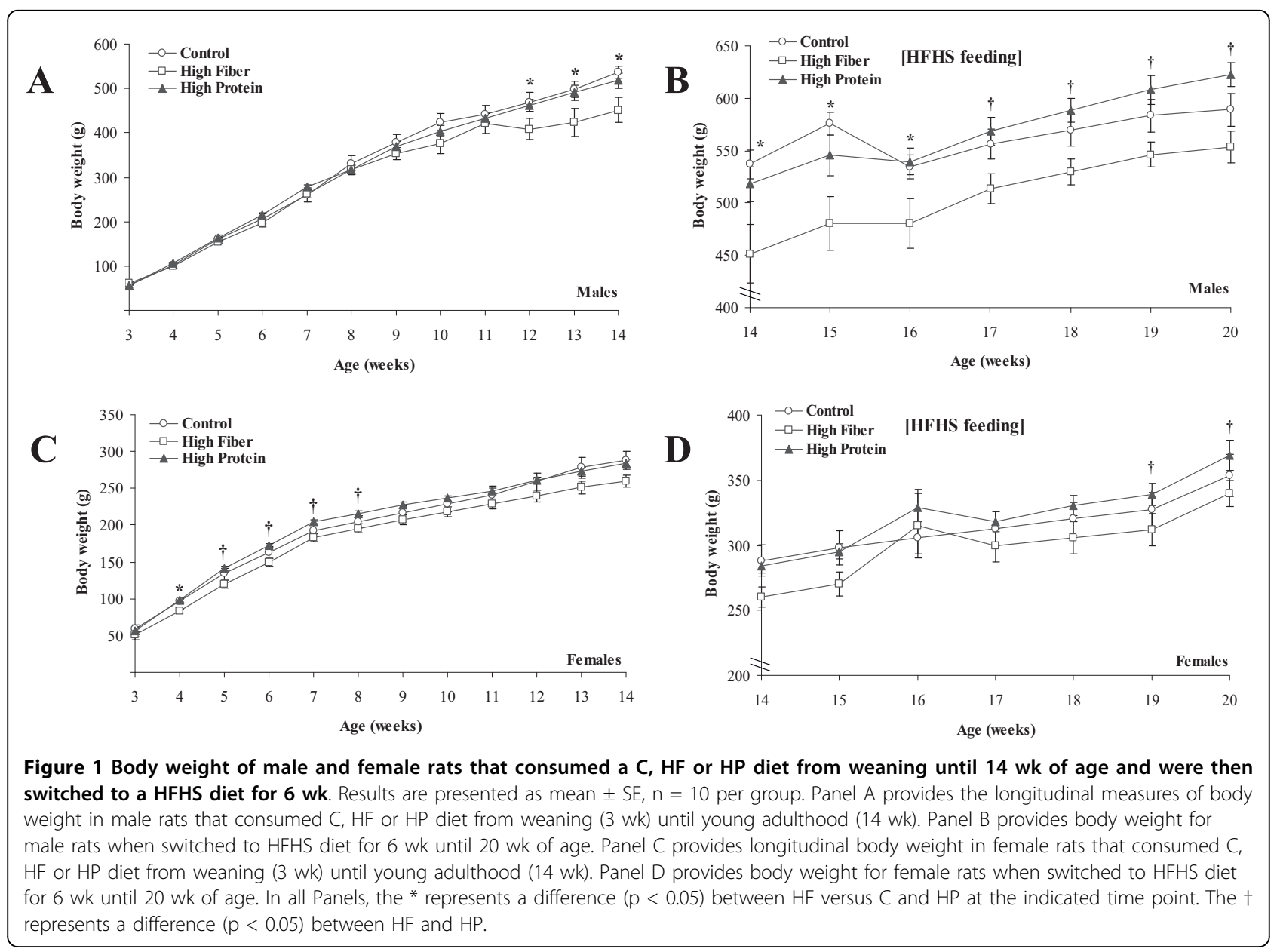


Table 2 Body composition in rats switched from control, high fiber or high protein weaning diets to a high fat, sucrose diet in adulthood

\begin{tabular}{lllllll}
\hline & \multicolumn{2}{c}{ Control } & \multicolumn{2}{c}{ High Fiber } & \multicolumn{2}{c}{ High Protein } \\
& Male & Female & Male & Female & Male & Female \\
\hline Body weight (g) & $589.0 \pm 9.6^{\mathrm{ab}}$ & $353.5 \pm 6.1^{\mathrm{ab}}$ & $553.1 \pm 8.3^{\mathrm{a}}$ & $339.7 \pm 6.9^{\mathrm{a}}$ & $622.4 \pm 9.9^{\mathrm{b}}$ & $369.4 \pm 8.6^{\mathrm{b}}$ \\
Body fat (g) & $144.1 \pm 5.8^{\mathrm{a}}$ & $114.6 \pm 3.5^{\mathrm{ab}}$ & $133.6 \pm 5.4^{\mathrm{a}}$ & $93.1 \pm 5.3^{\mathrm{a}}$ & $224.7 \pm 22.3^{\mathrm{b}}$ & $139.3 \pm 19.2^{\mathrm{b}}$ \\
Lean mass (\%) & $75.5 \pm 1.0^{\mathrm{a}}$ & $67.6 \pm 1.0^{\mathrm{ab}}$ & $76.0 \pm 0.8^{\mathrm{a}}$ & $72.6 \pm 1.5^{\mathrm{a}}$ & $64.0 \pm 2.2^{\mathrm{b}}$ & $62.3 \pm 2.8^{\mathrm{b}}$ \\
\hline
\end{tabular}

Values are mean \pm SE with $n=9-10$ per group. Lean mass represents lean tissue plus bone mineral content. Two-way ANOVA revealed a significant sex ( $p<$ $0.005)$ and diet $(p<0.001)$ effect for all three parameters. Treatments with different letters are significantly different between diets within males or females respectively $(p<0.05)$.

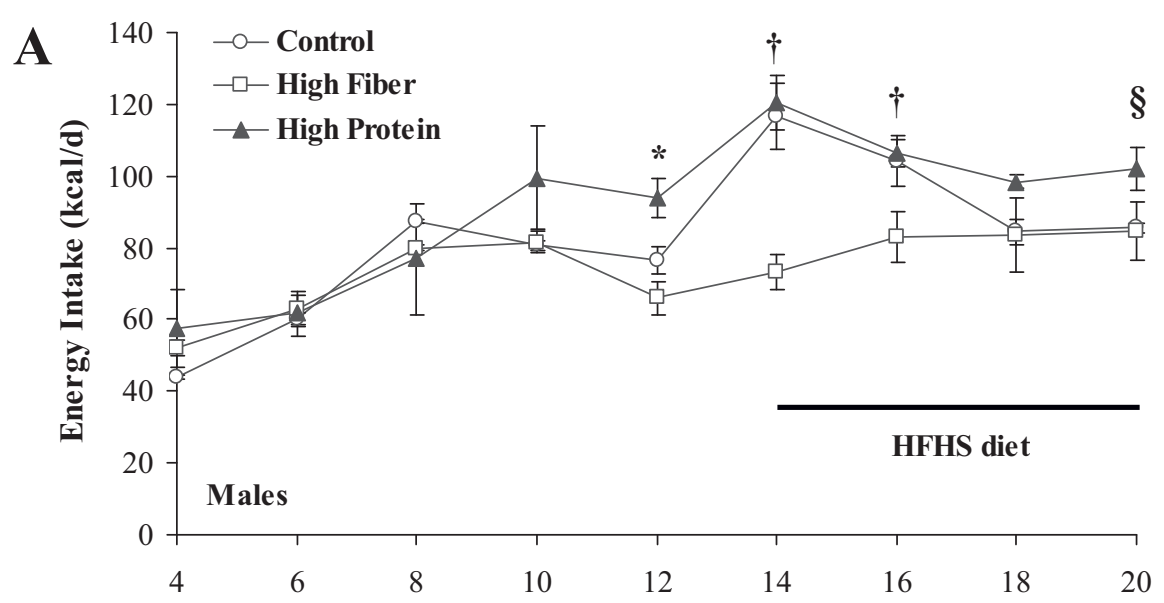

Weeks

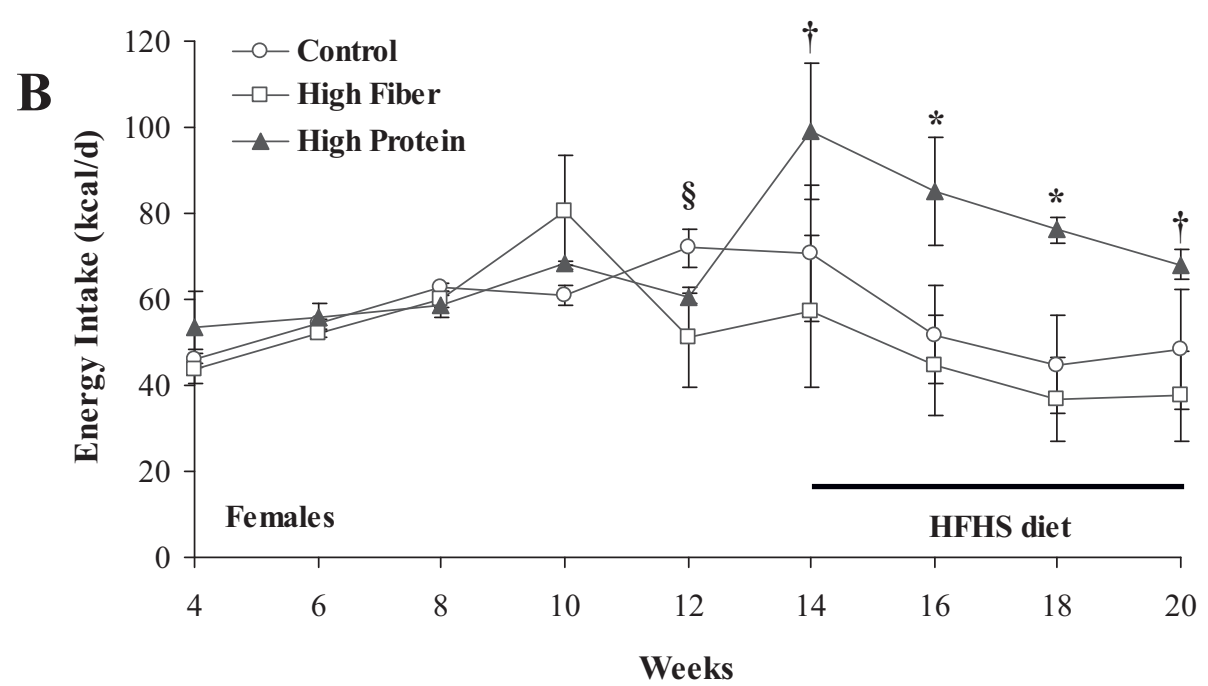

Figure 2 Energy intake of male and female rats that consumed a C, HF or HP diet from weaning until 14 wk of age and were then switched to a HFHS diet for $\mathbf{6} \mathbf{w k}$. Results are presented as mean $\pm S E, n=5$ per group. Panel A provides the energy intake in male rats measured daily for a week every two weeks throughout the study. Rats were switched from their weaning diet (C, HF or HP) to HFHS at 14 wk of age and consumed it until study completion at $20 \mathrm{wk}$ of age. Panel B provides the energy intake in female rats measured for daily for a week every two weeks throughout the study. In Panel $A$, the ${ }^{*}$ represents a difference $(p<0.05)$ between HP versus HF and $C$. The $\dagger$ represents a difference $(p<0.05)$ between HF versus HP and C. The $\S$ represents a difference $(p<0.05)$ between HP versus HF. In Panel B, the * represents a difference $(p<0.05)$ between HP versus HF and C. The $\dagger$ represents a difference $(p<0.05)$ between HF versus HP. The $\S$ represents a difference $(p<0.05)$ between HF versus $C$. 
Table 3 Body weight adjusted intestinal characteristics of rats switched from control, high fiber or high protein weaning diets to a high fat, sucrose diet in adulthood

\begin{tabular}{|c|c|c|c|c|c|c|}
\hline \multirow[t]{2}{*}{ Parameter } & \multicolumn{2}{|c|}{ Control } & \multicolumn{2}{|c|}{ High Fiber } & \multicolumn{2}{|c|}{ High Protein } \\
\hline & Male & Female & Male & Female & Male & Female \\
\hline Liver Weight (mg/g) & $21.6 \pm 0.3$ & $21.2 \pm 0.7$ & $21.3 \pm 0.7$ & $23.3 \pm 0.7$ & $23.2 \pm 0.8$ & $20.4 \pm 0.7$ \\
\hline Small Intestine Length $(\mathrm{mm} / \mathrm{g})$ & $2.09 \pm 0.04^{a}$ & $3.27 \pm 0.01^{a}$ & $2.31 \pm 0.03^{b}$ & $3.63 \pm 0.01^{b}$ & $2.01 \pm 0.04^{a}$ & $3.19 \pm 0.01^{a}$ \\
\hline Small Intestine Weight (mg/g) & $11.2 \pm 0.2^{\mathrm{a}}$ & $16.2 \pm 0.3^{a}$ & $12.9 \pm 0.3^{b}$ & $16.5 \pm 0.3^{b}$ & $12.2 \pm 0.2^{b}$ & $15.7 \pm 0.3^{a}$ \\
\hline Colon Length $(\mathrm{mm} / \mathrm{g})$ & $0.32 \pm 0.01$ & $0.38 \pm 0.03^{a}$ & $0.36 \pm 0.01$ & $0.60 \pm 0.03^{b}$ & $0.32 \pm 0.01$ & $0.52 \pm 0.03^{a b}$ \\
\hline Colon Weight (mg/g) & $2.5 \pm 0.1^{\mathrm{a}}$ & $3.4 \pm 0.2^{\mathrm{a}}$ & $3.3 \pm 0.2^{b}$ & $4.2 \pm 0.2^{b}$ & $2.6 \pm 0.1^{\mathrm{a}}$ & $3.4 \pm 0.2^{a}$ \\
\hline Empty Cecum Weight (mg/g) & $1.2 \pm 0.1^{\mathrm{a}}$ & $2.0 \pm 0.2^{a}$ & $2.7 \pm 0.2^{b}$ & $3.3 \pm 0.2^{b}$ & $1.3 \pm 0.1^{a}$ & $1.7 \pm 0.2^{a}$ \\
\hline
\end{tabular}

Values are mean \pm SE with control $(n=9 M ; n=9$ F); high fiber $(n=10 M ; n=10 F)$; and high protein $(n=10 M ; n=10 F)$. There was a significant diet effect $(p$ $<0.01$ ) for small intestine length and weight, colon length and weight, and cecum weight as determined with two-factor ANOVA. There was a significant sex effect $(p<0.01)$ for small intestine length and weight, colon length and weight, stomach weight, and cecum weight as determined by two-way ANOVA. There was a significant diet by sex effect for colon length $(p=0.008)$. Values with different letters are significantly different $(p<0.05)$ within males or females.

Organ weights, expressed as a proportion of individual total body weight, were calculated and are presented in Table 3. For both males $(p=0.003)$ and females $(p=0.001)$, adjusted small intestine length was greater with HF than HP and C. Small intestine weight was greater in HF $(\mathrm{p}<0.001)$ and HP ( $\mathrm{p}=0.05)$ compared to $\mathrm{C}$ in males. In females, HF was greater than $\mathrm{C}(\mathrm{p}=0.01)$ and HP $(\mathrm{p}=0.04)$. Colon length was greater with HF compared to $C(p<0.001)$ in females only. The HF diet resulted in significantly higher colon weight than the $C(p<0.01)$ and HP groups $(p<0.01)$ in both males and females. Empty cecum weight was significantly higher in rats consuming a HF diet compared to $C$ and HP in males and females $(p<0.001)$.

\section{Plasma hormones and blood glucose}

There was a significant diet effect for glucose wherein concentrations were higher for $\mathrm{HP}$ rats compared to $\mathrm{HF}$ at time 30, 60, and $90 \mathrm{~min}(\mathrm{p}<0.05$; Figure 3A). There were no significant differences in insulin between the groups (Figure 3B). A significant sex effect was found for amylin therefore male and female data were analysed separately. There was a significant diet effect for amylin in female rats $(\mathrm{p}=0.014$; Figure $3 \mathrm{C}$ ) but not male rats (Figure 3D). HF was greater than $\mathrm{C}$ in females at time 0 $(\mathrm{p}=0.01), 15(\mathrm{p}=0.02)$, and 60 minutes $(\mathrm{p}=0.05)$. GLP1 was significantly higher in HF rats than HP throughout the entire OGTT ( $<<0.05$; Figure 4A). Glucagon release was suppressed following the oral glucose load but did not differ between groups (Figure 4B). There were significant diet effects for leptin wherein HP was greater than $\mathrm{HF}$ and $\mathrm{C}$ at time 0 and time 60 ( $\mathrm{p}<0.05)$, and greater than $\mathrm{HF}$ at time 15 ( $\mathrm{p}<0.05$; Figure $4 \mathrm{C})$.

\section{Intestinal and hepatic gene expression}

In the duodenum, HP was associated with lower SGLT-1 mRNA expression compared to $C$ ( $p<0.05$; Figure $5 \mathrm{~A})$. $\mathrm{HF}$ was associated with an increase in the glucose transporter, GLUT5 mRNA compared to HP ( $\mathrm{p}=0.012)$. In the jejunum, both $\mathrm{C}(\mathrm{p}=0.026)$ and $\mathrm{HF}(\mathrm{p}=0.009)$ were associated with greater GLUT5 mRNA expression than HP. There were no differences in intestinal proglucagon mRNA expression. In the liver, HF was associated with a significant reduction in hepatic hydroxymethylglutaryl coenzyme A (HMG-CoA) reductase mRNA compared to $C(p=0.001)$ and $H P(p=0.05)$ (Figure $5 B)$. The expression of hepatic cholesterol 7- $\alpha$ hydroxylase (CYP) mRNA was lower $(\mathrm{p}=0.006)$ in rats fed HP compared to $C$. The HP diet was associated with higher expression of GLUT2 mRNA compared to HF ( $p=0.03)$, and higher glucokinase mRNA compared to $C(p=0.03)$. There were, however, no significant diet differences in acetyl CoA carboxylase (ACC), fatty acid synthase (FAS), sterol regulatory element binding protein (SREBP)-1c, SREBP-2, lecithin cholesterol acyl transferase (LCAT) or leptin mRNA in the liver.

\section{Hepatic triglyceride and cholesterol content}

There were significant sex $(\mathrm{p}<0.001)$ and diet $(\mathrm{p}=0.001)$ effects for hepatic triglyceride content (Figure 6). In male rats, HP had higher triglyceride content than $C(p=0.021)$ and HF ( $p=0.001)$. There was a significant sex effect $(\mathrm{p}=0.014)$ for cholesterol content but no diet effect.

\section{Discussion}

As obesity rates escalate, it has become imperative to identify factors that contribute to the development of obesity and its comorbidities. The risk of developing the metabolic syndrome, a combination of risk factors predisposing individuals to cardiovascular and type 2 diabetes, has been shown to be particularly sensitive to nutritional influences early in life [27]. Most animal studies have used two major models of metabolic programming, that of maternal undernutrition to probe prenatal influences [28], and litter size manipulation to examine postnatal under- and overnutrition during the suckling 

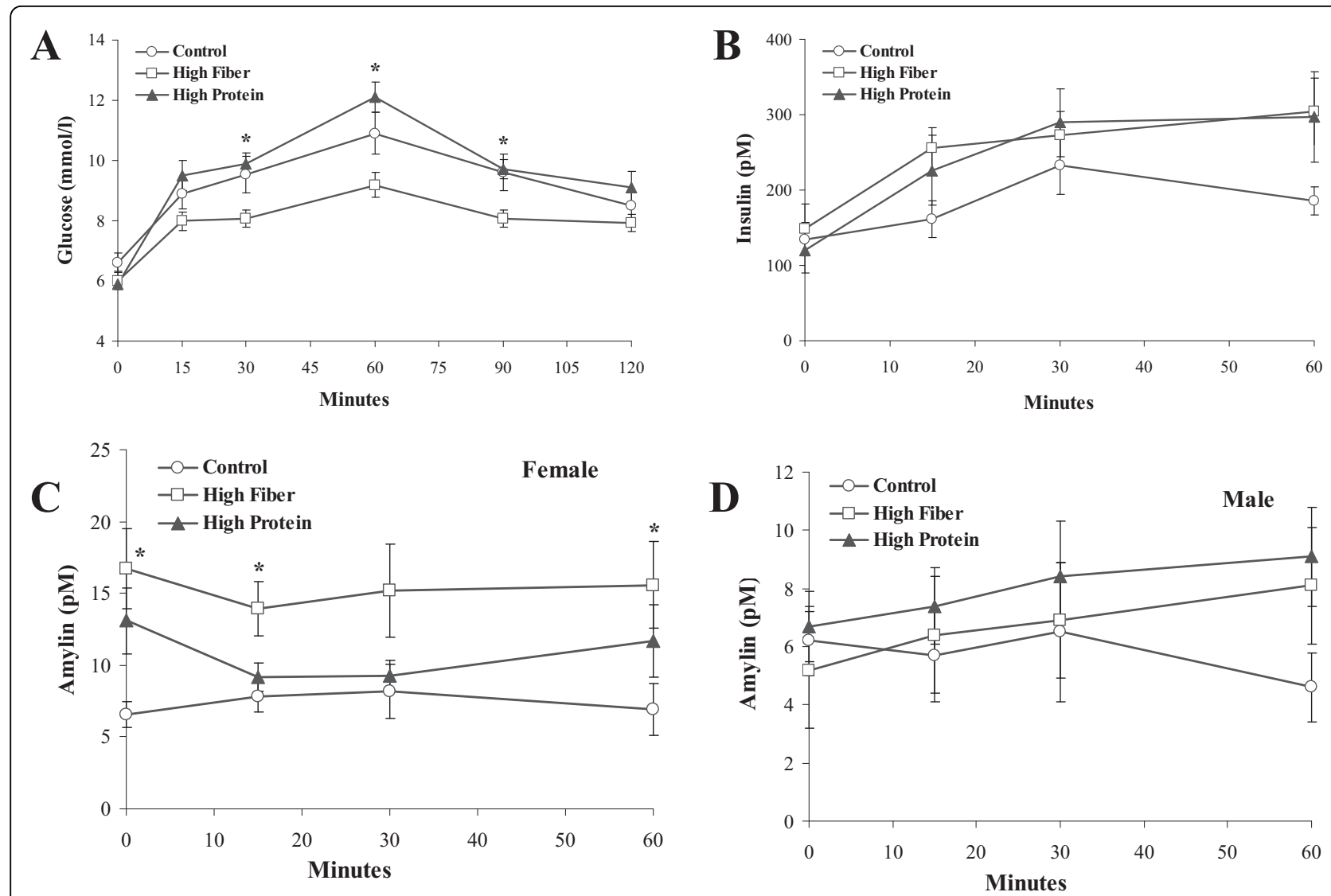

Figure 3 Blood glucose and plasma insulin and amylin in rats during an oral glucose tolerance test following a high fat/sucrose diet challenge. Results are presented as mean $\pm \mathrm{SE}, \mathrm{n}=8-9$ per group. Panel A provides the serial values of blood glucose during the OGTT. No sex effect was detected for glucose or insulin, therefore male and female data were combined. The * in Panel A represents a difference $(p<0.05)$ between HF versus HP and C. Panel B provides the serial values of plasma insulin. Panel C provides the serial values of amylin in female rats. In Panel $C$, the ${ }^{*}$ represents a difference $(p<0.05)$ between $\mathrm{HF}$ and $C$ at the indicated time points. Panel $D$ provides the serial values of amylin in male rats.

period [29]. Much less work has examined the effects of maternal overnutrition and even less work has probed the effect of increased intake of select nutrients in the early postnatal period. Therefore, we examined the consequences of consuming a high prebiotic fiber or high protein diet throughout growth followed by a high energy diet challenge in adulthood.

The present study demonstrates that a long-term weaning diet high in fiber or protein results in significant differences in body weight and fat mass, the secretion of select satiety hormones, and the expression of genes involved in glucose and lipid metabolism in response to a high energy diet in adulthood. Our major findings include: 1) an increase in body weight and fat mass in response to high energy diets after a weaning diet high in protein compared to fiber; 2) an increase in energy intake in rats fed a HP diet, especially when switched to a HFHS diet; 3 ) a decrease in glucose and increase in GLP-1 in rats fed HF; and 4) greater accumulation of triglyceride in the liver of HP-fed rats. Take together, this data suggest that the response to a high energy diet challenge in adulthood results in greater metabolic dysfunction (ie. increased fat mass, decreased glucose tolerance, reduced GLP-1 secretion, greater hepatic triglyceride content) when a HP diet is consumed from weaning into early adulthood compared to a HF diet.

The increase in the relative mass of the small intestine, colon and cecum in the HF group is consistent with our previous work with fiber-enriched diets $[10,11,24]$. Addition of readily fermentable fiber to a diet is known to cause a significant proliferative effect in the colon and distal small intestine [30]. The prebiotic fibers, inulin and oligofructose, are highly water soluble and non-viscous and stimulate lactic-acid bacteria growth in the gut [31]. Inulin, chiefly derived from chicory, and its hydrolysis product, oligofructose, are fructans that have $\beta$-(2-1) linkages that differ in a high (inulin) and low (oligofructose) number of fructose 


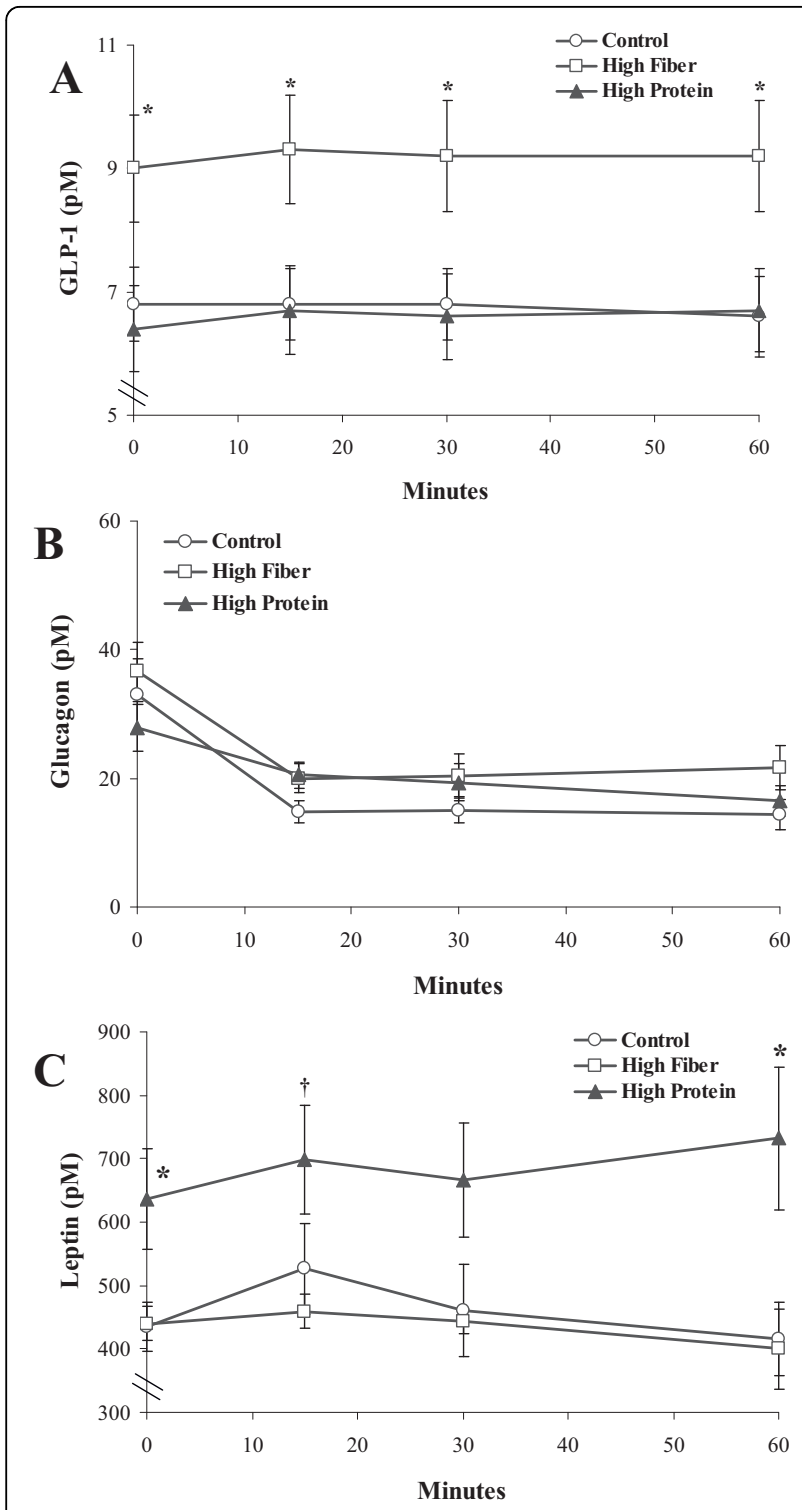

Figure 4 Plasma GLP-1, glucagon and leptin in rats during an oral glucose tolerance test following a high fat/sucrose diet challenge. Results are presented as mean $\pm \mathrm{SE}, \mathrm{n}=8-9$ per group. No sex effect was detected for GLP-1, glucagon and leptin,

therefore male and female data were combined. Panel A provides the serial values of plasma GLP-1 during the OGTT. In Panel A, the * represents a difference $(p<0.05)$ between HF and HP at the indicated time points. Panel B provides the serial values of plasma glucagon. Panel C provides the serial values of leptin. In Panel C, the * represents a difference $(p<0.05)$ between HP versus HF and $C$. The $†$ represents a difference $(p<0.05)$ between HP and HF at 15 minutes.

molecules [32]. Reductions in body weight and fat mass [33], enhanced satiety [34], improved glucose control in hyperglycaemic subjects [35], increased GLP-1 secretion [36] and improved blood lipid profiles have all been demonstrated in humans consuming oligofructose [37].
GLP-1 is released from L cells in the intestine in response to food ingestion and has been shown to slow gastric emptying and decrease food intake and body weight [38]. We have previously shown that a diet high in fiber increases plasma GLP-1 concentrations $[10,11,24]$. There is some controversy surrounding the role of anorexigenic hormones, including GLP-1, in enhancing satiety with HP diets [39]. This study demonstrates that HF caused a significant sustained release of GLP-1 which was not observed in the HP or C rats. This increase is in agreement with work by others feeding oligofructose [40-42]. Similarly, amylin, a pancreatic $\beta$-cell hormone that inhibits food intake [43] was also increased by the HF diet in females. No significant differences between groups were seen in males which is likely due to the large variability observed in the males. Our observations of increased amylin in the HF-fed female rats is in agreement with that seen by Cani et al. [44] wherein consumption of the prebiotic fiber, oligofructose, increased amylin in $o b / o b$ mice. The change in these two anorexigenic hormones lends support for the lower energy intake observed in the HF rats both in periods of direct exposure to the prebiotic but also in the period where all rats consumed the HFHS diet. The increase in body weight and energy intake was greatest in HP rats when they were introduced to the HFHS diet suggesting that consuming the HP diet from weaning to early adulthood did not protect them against the obesigenic effects of the HFHS diet. In fact, although final body weight did not differ between $\mathrm{C}$ and HP rats, the markedly higher body fat in the HP rats is metabolically harmful and suggests that a significant shift in nutrient partitioning occurred in these rats. On the other hand by consuming the high prebiotic diet throughout growth, HF rats were protected against excessive weight gain and fat mass accumulation when challenged with the HFHS diet. And even though the HF rats entered the HFHS diet challenge at a lower body weight they did not catch up this weight during the high energy feeding as weight gain remained significantly lower in HF versus HP rats during the final six weeks of the study. The mechanisms responsible for these contrasting protective and detrimental effects are not completely know but could involve changes in metabolism.

The expression of certain genes involved in glucose and lipid metabolism was altered with diet and these could exert effects that ultimately influence body composition. HMG-CoA reductase is the rate-limiting enzyme in cholesterol synthesis. Serum cholesterol can be reduced by administration of HMG-CoA reductase inhibitors and these are often prescribed to achieve reductions in LDL cholesterol [45]. We observed a significant decrease in $\mathrm{HMG}-\mathrm{CoA}$ reductase mRNA expression in the liver of rats fed a long-term diet of 

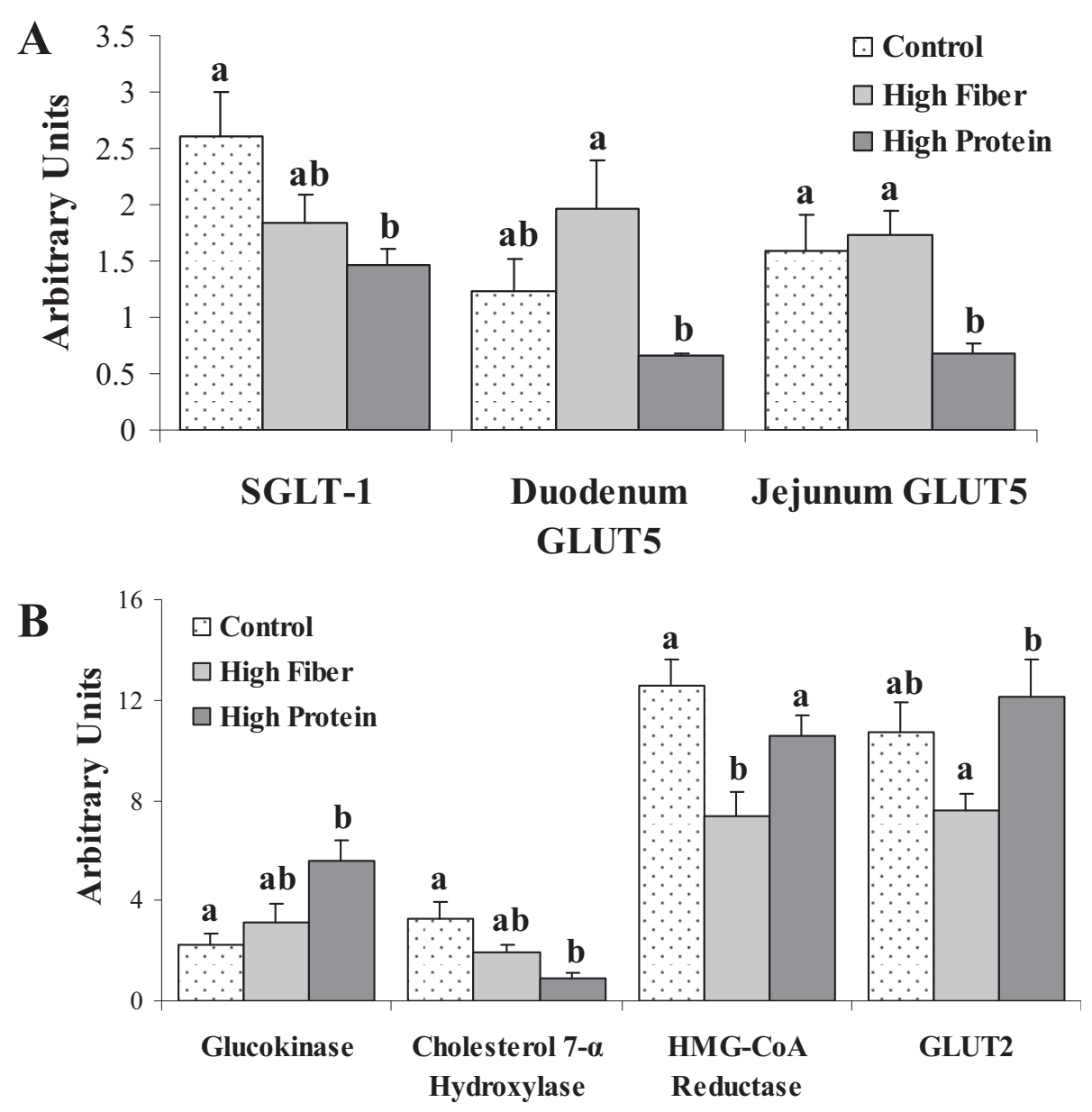

Figure 5 Gene expression in the intestine (A) and liver (B) of rats challenged with a high fat/sucrose diet following HP, HF or C diets. Results are presented as mean $\pm S E, n=9-10$ per group. No sex effect was detected, therefore male and female data were combined. Diet treatments with different letters within a gene represent a significant difference $(p<0.05)$. Sodium-dependent glucose transporter (SGLT-1), glucose transporter (GLUT); hydroxymethylglutaryl coenzyme A reductase (HMG-CoA reductase.

high fiber which persisted even after both groups consumed the HFHS diet. A HFHS diet has been shown to increase hepatic HMG-CoA reductase mRNA in rats [46]. Given that all of our rats were fed HFHS diet for the last 6 weeks of the study one might anticipate that HMG-CoA reductase would increase in all rats similarly but it is clear that the residual effects of the high fiber diet consumed throughout growth persisted in these animals to minimize this response.

Another potential drug target for lowering cholesterol is cholesterol $7 \alpha$-hydroxylase [47]. Cholesterol can be incorporated into bile salts by cholesterol $7 \alpha$-hydroxylase, the initial and rate-determining enzyme for bile synthesis [48]. We demonstrated that a high protein diet, when followed by a diet high in energy results in decreased expression of cholesterol $7 \alpha$-hydroxylase mRNA which could be indicative of decreased incorporation of cholesterol into bile acids and the potential for longer-term impairment in cholesterol metabolism in these rats.

Glucokinase (GK) catalyzes the rate-limiting step in glycolysis, the phosphorylation of glucose to glucose-6phospate. In the liver, GK activity determines the rate of glucose utilization and glycogen synthesis [49]. GK first appears in the liver of rats about 16 days after birth and reaches adult activity levels 10-12 days later [50]. There is little research on the effect of long-term high protein diets on glucokinase or GLUT2 activity. We demonstrated an increase in the expression of both genes in the liver due to a long-term weaning diet high in protein subsequently followed by the high energy diet. Although not demonstrated consistently, a high fat diet has been shown to increase hepatic GK mRNA [49,51]. While some would suggest that increased GK activity could improve hepatic insulin resistance [52], others have shown that long-term increased GK activity leads 

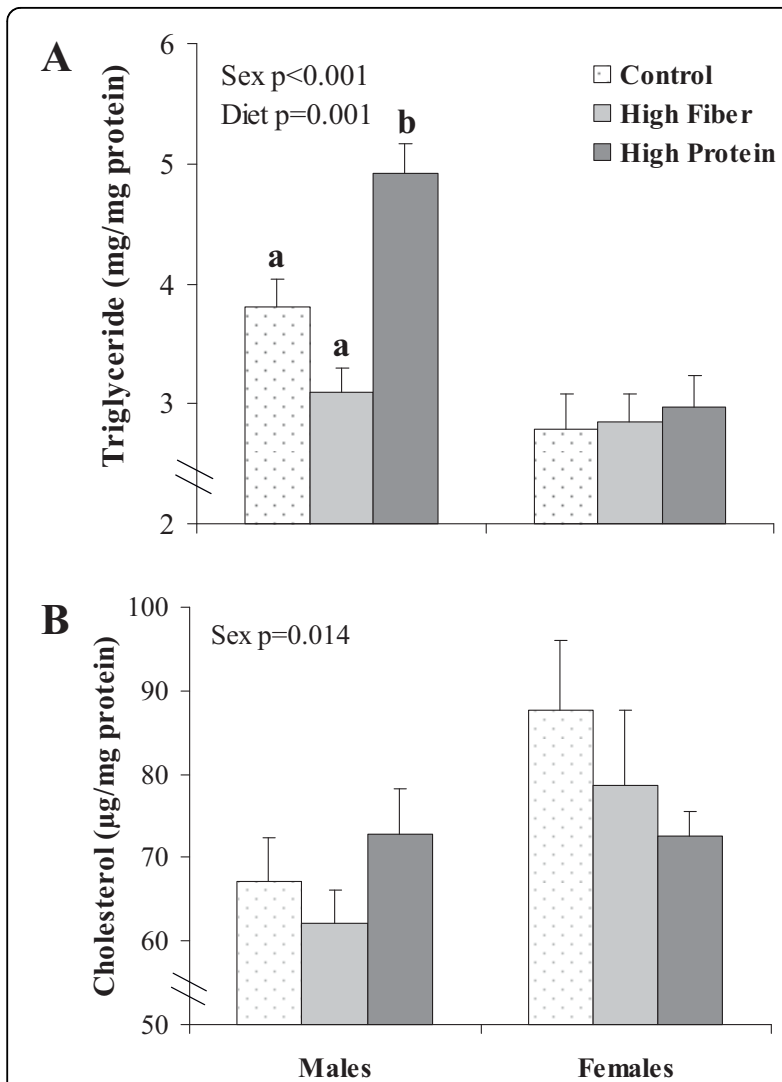

Figure 6 Hepatic triglyceride and cholesterol content in rats challenged with a high fat/sucrose diet following HP, HF or C diets. Results are presented as mean $\pm \mathrm{SE}, \mathrm{n}=$ 9-10 per group. Significant sex and diet effects are indicated in the graphs. Diet treatments with different letters within a gene represent a significant difference $(p<0.05)$.

to glucose intolerance and hepatic lipid accumulation in mice [53]. Mice over-expressing GK were also more sensitive to the diabetogenic effects of a high fat diet, which supports the elevated triglyceride content seen in our HP rats. Whether or not the increased GK mRNA seen in our high protein fed rats also played a role in the overall exacerbated negative response they had to the HFHS diet warrants further investigation.

The fructose transporter, GLUT5, is expressed in greatest concentration in the small intestine, but is also expressed in the kidneys, skeletal muscle and certain areas of the brain [54]. In rats, GLUT5 expression remains low until the completion of weaning and a switch to solid food [54]. It has been shown in individuals with type 2 diabetes that GLUT5 expression is higher in skeletal muscle [55] and in the intestines [56]. However, these findings are not consistent and remain controversial [54]. GLUT5 synthesis is regulated very quickly by diet as consumption of fructose results in an increase in the transporter within a few hours [57]. In the intestine of our rats fed a high protein diet we see a general down-regulation in the hexose transporters which likely reflects the lower carbohydrate content of this diet.

When we previously examined the expression of genes controlling glucose and lipid metabolism in young rats (days 7, 14, 21, 28, 35 of age) weaned onto high protein or fiber diets, we observed minimal change in gene expression in the intestine, and in the liver a decrease solely in FAS mRNA with HP and HF compared to control [23]. On the other hand, the greater GLP-1 levels we observed in these same young rats with high fiber diet [23] did persist into adulthood as demonstrated in the current study. Considered together, these studies comparing early and late changes to the diets would suggest that while some metabolic pathways (satiety hormones) are influenced very early on by diet, others (expression of genes regulating lipid metabolism) are only exasperated by a high energy diet in adulthood. The greater hepatic triglyceride content and fat mass in the high protein rats in this study provide phenotypic evidence for changes occurring at the level of gene expression.

\section{Conclusions}

Our research demonstrating a significant susceptibility to an obese phenotype in rats weaned onto a HP diet and then challenged in adulthood with a HFHS diet suggests that lasting changes result from altering the composition of the first solid food that is consumed throughout growth into early adulthood. While all rats in this study consumed the same high energy diet during the last 6 weeks of the intervention, distinct metabolic profiles remained evident from exposure to the different diets during growth. This would suggest that these changes, either long-lasting or perhaps permanent, ultimately influenced the adiposity response of these rats to a high energy challenge in adulthood. Overall, it appears that a long-term diet high in protein, when mismatched with a high energy challenge, has negative effects on body mass and hormones and genes involved in glucose and lipid metabolism. However, a fiber-enriched diet may provide some protection. Given the continued escalation in the rates of obesity worldwide, further research examining dietary composition during growth and the long-term protective or detrimental influences they exert are clearly warranted.

\section{Acknowledgements}

We thank Kristine Lee for her extensive technical help in this study. This work was supported with funding from the Natural Sciences and

Engineering Research Council. The funding was provided without constraint and the agencies were not involved in study design; in the collection, analysis, and interpretation of data; in the writing of the manuscript; or in the decision to submit the manuscript for publication. Special thanks to the Julia MacFarlane Diabetes Research Centre for a training award for ADM; and 
the Markin Undergraduate Student Research Program in Health and Wellness for a training award for $\mathrm{KT}$.

\section{Author details}

1 Department of Biochemistry and Molecular Biology, University of Calgary, 3280 Hospital Drive NW, Calgary, T2N 4Z6, Canada. ${ }^{2}$ Faculty of Kinesiology, University of Calgary, 2500 University Drive NW, Calgary, T2N 1N4, Canada.

\section{Authors' contributions}

ADM participated in the design of the study, carried out the plasma analysis and DEXA, performed statistical analysis and drafted the manuscript. LKE carried out the oral glucose tolerance test and interpreted the data. MCH participated in the oral glucose tolerance test and performed gene expression analysis. KT carried out the triglyceride and cholesterol analysis and the associated statistical analysis and interpretation of the data. RAR conceived of the study and participated in its design and coordination and edited the manuscript. All authors read and approved the final manuscript.

\section{Competing interests}

The authors declare that they have no competing interests.

Received: 18 February 2010 Accepted: 29 September 2010 Published: 29 September 2010

\section{References}

1. Bonow RO, Eckel RH: Diet, obesity and cardiovascular risk. N Engl J Med 2003, 348:2057-2058.

2. Wang $Y$, Lobstein T: Worldwide trends in childhood overweight and obesity. Int J Pediatric Obes 2006, 1:11-25.

3. Weiss R, Kaufman FR: Metabolic complications of childhood obesity: identifying and mitigating the risk. Diabetes Care 2008, 31:S310-\$316.

4. Key TJ, Spencer EA: Carbohydrates and cancer: an overview of the epidemiological evidence. Eur J Clin Nutr 2007, 61:S112-S121.

5. de Munter JS, Hu FB, Spiegelman D, Franz M, van Dam RM: Whole grain, bran, and germ intake and risk of type 2 diabetes: a prospective cohort study and systematic review. PLoS Med 2007, 4:e261.

6. Gaesser GA: Carbohydrate quantity and quality in relation to body mass index. J Am Diet Assoc 2007, 107:1768-1780.

7. Marlett JA, McBurney MI, Slavin JL: Position of the American Dietetic Association: health implications of dietary fiber. J Am Diet Assoc 2002, 102:993-1000.

8. Lundin EA, Zhang JX, Lairon D, Tidehag P, Aman P, Adlercreutz H, Hallmans G: Effects of meal frequency and high-fibre rye-bread diet on glucose and lipid metabolism and ileal excretion of energy and sterols in ileostomy subjects. Eur J Clin Nutr 2004, 58:1410-1419.

9. Wang ZQ, Zuberi AR, Zhang XH, Macgowan J, Qin J, Ye X, Son L, Wu Q, Lian K, Cefalu WT: Effects of dietary fibers on weight gain, carbohydrate metabolism, and gastric ghrelin gene expression in mice fed a high-fat diet. Metabolism 2007, 56:1635-1642.

10. Reimer RA, McBurney MI: Dietary fiber modulates intestinal proglucagon messenger ribonucleic acid and postprandial secretion of glucagon-like peptide-1 and insulin in rats. Endocrinology 1996, 137:3948-3956.

11. Reimer RA, Thomson ABR, Rajotte R, Basu TK, Ooraikul B, McBurney MI: A physiological level of rhubarb fiber increases proglucagon gene expression and modulates intestinal glucose uptake in rats. J Nutr 1997, 127:1923-1928.

12. Atkins RC: Dr. Atkins' New Diet Revolution New York: Avon Books 1992

13. Paddon-Jones D, Westman E, Mattes RD, Wolfe RR, Astrup A, WesterterpPlantenga M: Protein, weight management, and satiety. Am J Clin Nutr 2008, 87:1558S-1561S.

14. Parker B, Noakes M, Luscombe N, Clifton P: Effect of a high-protein, highmonounsaturated fat weight loss diet on glycemic control and lipid levels in type 2 diabetes. Diabetes Care 2002, 25:425-430.

15. Farnsworth E, Luscombe ND, Noakes M, Wittert G, Argyiou E, Clifton PM: Effect of a high-protein, energy-restricted diet on body composition, glycemic control, and lipid concentrations in overweight and obese hyperinsulinemic men and women. Am J Clin Nutr 2003, 78:31-39.

16. Brinkworth GD, Noakes M, Parker B, Foster P, Clifton PM: Long-term effects of advice to consume a high-protein, low-fat diet, rather than a conventional weight-loss diet, in obese adults with type 2 diabetes: one-year follow-up of a randomised trial. Diabetologia 2004, 47:1677-1686.
17. Long SJ, Jeffcoat AR, Millward DJ: Effect of habitual dietary-protein intake on appetite and satiety. Appetite 2000, 35:79-88.

18. Lucas A: Programming by early nutrition: an experimental approach. J Nutr 1998, 128:410S-406S.

19. Barker DJ: Obesity and early life. Obes Rev 2007, 8:45-49.

20. Barker DJ: The developmental origins of adult disease. J Am Coll Nutr 2004, 23:588S-595S.

21. Hanson MA, Gluckman PD: Developmental origins of health and disease: new insights. Basic \& Clinical Pharmacology \& Toxicology 2008, 102:90-93.

22. Godfrey KM, Lillycrop KA, Burdge GC, Gluckman PD, Hanson MA: Epigenetic mechanisms and the mismatch concept of the developmental origins of health and disease. Pediatr Res 2007, 61:5R-10R.

23. Maurer AD, Chen $Q$, McPherson C, Reimer RA: Changes in satiety hormones and expression of genes involved in glucose and lipid metabolism in rats weaned onto diets high in fiber or protein reflect susceptibility to increased fat mass in adulthood. J Physiol Lond 2009, 587:679-691.

24. Reimer RA, Russell JC: Glucose tolerance, lipids and GLP-1 secretion in JCR:LA-cp rats fed a high protein fiber diet. Obesity 2008, 16:40-46.

25. Livak KJ, Schmittgen TD: Analysis of relative gene expression data using real-time quantitative PCR and the $2^{-\Delta \Delta C T}$ method. Methods 2001, 25:402-408.

26. Parnell JA, Reimer RA: Effect of prebiotic fiber supplementation on hepatic gene expression and serum lipids: a dose-response study in JCR: LA-cp rats. Br J Nutr 2009, 103:1577-1584.

27. Barker DJ, Eriksson JG, Forsen T, Osmond C: Fetal origins of adult disease: strength of effects and biological basis. Int J Epidemiol 2002, 31:1235-1239.

28. Shepherd PR, Crowther NJ, Desai M, Hales CN, Ozanne SE: Altered adipocyte properties in the offspring of protein malnourished rats. $\mathrm{Br} \mathrm{J}$ Nutr 1997, 78:121-129.

29. Hahn P: Effect of litter size on plasma cholesterol and insulin and some liver and adipose tissue enzymes in adult rodents. J Nutr 1984, 114:1231-1234.

30. Jacobs $L R$, Lupton JR: Effect of dietary fibers on rat large bowel mucosal growth and cell proliferation. Am J Physiol 1984, 246:G378-G385.

31. Delzenne NM: Oligosaccharides: state of the art. Proc Nutr Soc 2003, 62:177-182.

32. Roberfroid MB: Prebiotics: preferential substrates for specific germs? Am J Clin Nutr 2001, 73:406S-409S

33. Parnell JA, Reimer RA: Weight loss during oligofructose supplementation is associated with decreased ghrelin and increased peptide $Y Y$ in overweight and obese adults. Am J Clin Nutr 2009, 89:1751-1759.

34. Cani PD, Joly E, Horsmans $Y$, Delzenne NM: Oligofructose promotes satiety in healthy humans: a pilot study. Eur J Clin Nutr 2006, 60:567-572.

35. Yamashita K, Itakura M, Kawai K: Effect of fructo-oligosaccharides on blood glucose and serum lipids in diabetic subjects. Nutr Res 1984, 4:961-966.

36. Piche T, des Varannes SB, Sacher-Huvelin S, Holst JJ, Cuber JC, Galmiche JP: Colonic fermentation influences lower esophageal sphincter function in gastroesophageal reflux disease. Gastroenterology 2003, 124:894-902.

37. Delzenne NM, Williams CM: Prebiotics and lipid metabolism. Curr Opin Lipidol 2002, 13:61-67.

38. Valassi E, Scacchi M, Cavagnini F: Neuroendocrine control of food intake. Nutr Metab Cardiovasc Dis 2008, 18:158-168.

39. Veldhorst M, Smeets A, Soenen S, Hochstenbach-Waelen A, Hursel R, Diepvens K, Lejeune M, Luscombe-Marsh N, Westerterp-Plantenga M: Protein-induced satiety: effects and mechanisms of different proteins. Physiol Behav 2008, 94:300-307.

40. Cani PD, Dewever C, Delzenne NM: Inulin-type fructans modulate gastrointestinal peptides involved in appetite regulation (glucagon-like peptide-1 and ghrelin) in rats. Br J Nutr 2004, 92:521-526.

41. Cani PD, Daubioul CA, Reusens B, Remacle C, Catillon G, Delzenne NM: Involvement of endogenous glucagon-like peptide-1(7-36) amide on glycemia-lowering effect of oligofructose in streptozotocin-treated rats. $J$ Endocrinology 2005, 185:457-465.

42. Cani PD, Knauf C, Iglesias MA, Drucker DJ, Delzenne NM, Burcelin R: Improvement of glucose tolerance and hepatic insulin sensitivity by oligofructose requires a functional glucagon-like peptide-1 receptor. Diabetes 2006, 55:1484-1490. 
43. Mack C, Wilson J, Athanacio J, Reynolds J, Laugero K, Guss S, Vu C, Roth J, Parkes D: Pharmacological actions of the peptide hormone amylin in the long-term regulation of food intake, food preference, and body weight. Am J Physiol Regul Integr Comp Physiol 2007, 293:R1855-R1863.

44. Cani PD, Possemiers S, Van de Wiele T, Guiot Y, Everard A, Rottier O, Geurts L, Naslain D, Neyrinck A, Lambert DM, Muccioli GG, Delzenne NM: Changes in gut microbiota control inflammation in obese mice through a mechanism involving GLP-2-driven improvement in gut permeability. Gut 2009, 58:1091-1103.

45. Jenkins DJ, Kendall CW, Marchie A, Faulkner DA, Josse AR, Wong JM, de Souza R, Emam A, Parker TL, Li TJ, Josse RG, Leiter LA, Singer W,

Connelly PW: Direct comparison of dietary portfolio vs statin on Creactive protein. Eur J Clin Nutr 2005, 59:851-860.

46. Lin C, Yin M: Effects of cysteine-containing compounds on biosynthesis fo triacylglycerol and cholesterol and anti-oxidative protection in liver from mice consuming high fat diet. Br J Nutr 2008, 99:37-43.

47. Gilardi F, Mitro N, Godio C, Scotti E, Caruso D, Crestani M, De Fabiani E: The pharmacological exploitation of cholesterol 7alpha-hydroxylase, the key enzyme in bile acid synthesis: from binding resins to chromatin remodelling to reduce plasma cholesterol. Pharmacol Ther 2007, 116:449-472.

48. Shefer $\mathrm{S}$, Hauser $\mathrm{S}$, Bekersky I, Mosbach EH: Biochemical site of regulation of bile acid biosynthesis in the rat. J Lipid Res 1970, 11:404-411.

49. Gorman T, Hope DCD, Brownlie R, Yu A, Gill D, Lofvenmark J, Wedin J, Mayers RM, Snaith MR, Smith DM: Effect of high-fat diet on glucose homeostasis and gene expression in glucokinase knockout mice. Diabetes Obes Metab 2008, 10:885-897.

50. Walker DG, Holland G: The development of hepatic glucokinase in the neonatal rat. Biochem J 1965, 97:845-854

51. Perez-Echarri N, Perez-Matute P, Marcos-Gomez B, Marti A, Martinez JA, Moreno-Aliaga MJ: Down-regulation in muscle and liver lipogenic genes: EPA ethyl ester treatment in lean and overweight (high-fat-diet) rats. J Nutr Biochem 2009, 20:705-714.

52. Zhang HJ, Ji BP, Chen G, Zhou F, Luo YC, Yu HQ, Gao FY, Zhang ZP, Li HY: A combination of grape seed-derived procyanidins and glypenosides alleviates insulin resistance in mice and HepG2 cells. J Food Science 2009, 74: $\mathrm{H} 1-\mathrm{H} 7$.

53. Ferre T, Riu E, Franckhauser S, Agudo J, Bosch F: Long-term overexpression of glucokinase in the liver of transgenic mice leads to insulin resistance. Diabetologia 2003, 46:1662-1668.

54. Douard V, Ferraris RP: Regulation of the fructose transporter GLUT5 in health and disease. Am J Physiol Endocrinol Metab 2008, 295:E227-E237.

55. Stuart CA, Howell ME, Yin D: Overexpression of GLUT5 in diabetic muscle is reversed by pioglitazone. Diabetes Care 2007, 30:925-931.

56. Dyer J, Wood IS, Palejwala A, Ellis A, Shirazi-Beechey SP: Expression of monosaccharide transporters in intestine of diabetic humans. Am J Physiol Gastrointest Liver Physiol 2002, 282:G241-G248.

57. Ferraris RP: Dietary and developmental regulation of intestinal sugar transport. Biochem J 2001, 360:265-276.

doi:10.1186/1743-7075-7-77

Cite this article as: Maurer et al:: Consumption of diets high in prebiotic fiber or protein during growth influences the response to a high fat and sucrose diet in adulthood in rats. Nutrition \& Metabolism 2010 7:77.

\section{Submit your next manuscript to BioMed Central and take full advantage of:}

- Convenient online submission

- Thorough peer review

- No space constraints or color figure charges

- Immediate publication on acceptance

- Inclusion in PubMed, CAS, Scopus and Google Scholar

- Research which is freely available for redistribution 